\title{
ANALISIS PENGARUH VARIAN MODEL PROPAGASI TERHADAP KOMUNIKASI DATA PADA PROTOKOL ROUTING TORA, MDART DAN ZRP DI JARINGAN VANET (STUDI KASUS PETA JALAN KOTA PRAYA DAN BYPASS LOMBOK)
}

\author{
(Analysis of Effect Propagation Model Variants on Data Comunication on TORA, \\ MDART and ZRP Routing Protocols In VANET \\ (Case Study : Praya City and Lombok Bypass Road Map)) \\ Priya Tama Sugara*, Andy Hidayat Jatmika, Ariyan Zubaidi \\ Program Studi teknik Informatika, Fakultas Teknik, Universitas Mataram \\ JI. Majapahit 62, Mataram, Lombok NTB, INDONESIA \\ Email: tamapriya6@gmail.com, [andy, ariyan.zubaidi]@unram.ac.id
}

\begin{abstract}
Vehichular Ad-hoc Network is part of the Mobile Ad-hoc Network (MANET), but the nodes on VANET have a higher level of mobility. Each node that moves will cause network activity (topology changes) such as route search and message sending handled by each node. So that each node must have a routing protocol to facilitate communication in the network. The selection of the appropriate routing protocol is needed in urban and rural scenarios.This study aims to determine the effect of propagation model variants on data communication on the TORA, MDART and ZRP routing protocols on the VANET network on the Praya City and Bypass Lombok road maps with an area of $1000 x 1000$ m2. For the variation of the routing protocol using four variations of the propagation model, namely the freespace propagation model, tworayground, shadowing, and nakagami. The number of nodes used in the Praya City road map is 35, 55, 70 nodes and in Lombok Bypass 25, 40, 60 nodes. The test parameters used are throughput, packet delivery ratio and end to end delay.In an urban scenario with an area of $1000 \times 1000 \mathrm{~m}^{2}$, the results in urban scenarios the best average value in the TORA protocol througput parameter is $35.50 \mathrm{Kbps}$ in the nakagami propagation, from the rural scenario in the MDART protocol PDR parameters the average value is $99.54 \%$ in the shadowing propagation and for the delay parameter is 7,10 seconds on freespace propagation.
\end{abstract}

Keywords: VANET, TORA, MDART, ZRP, Propagation, NS2

*Penulis Korespondensi

\section{Pendahuluan}

Teknologi Informasi dan Komunikasi telah banyak membantu produktivitas manusia yang semakin meningkat. Saat ini kemajuan teknologi tidak dapat dibendung, perangkat komunikasi bergerak terus mengalami perkembangan yang sangat pesat yang memfasilitasi aktivitas manusia yang semakin mobile yaitu mengerjakan apapun, kapanpun dan dimanapun. Hal ini membuat suatu hal yang dikerjakan akan semakin mudah dilakukan seperti berkomunikasi dan bertukar data di lingkungan jalan raya menggunakan kendaraan, dimana aktivitas kendaraan cenderung dilakukan secara mobile.

Dalam dunia jaringan nirkabel, penerapan komunikasi data di lingkungan jalan raya dinamakan jaringan Vehicular Ad-hoc Network (VANET). Dalam konsep jaringan VANET, kendaraan diibaratkan sebuah node-node yang bergerak secara bebas dan mandiri. Kendaraan-kendaraan tersebut melakukan komunikasi dengan kendaraan-kendaraan lainnya di lingkungan jalan raya. Pergerakan node dalam VANET sangat tinggi yang menyebabkan seringnya topologi jaringan berubah-ubah. Hal ini akan berpengaruh pada rute yang telah terbentuk. Rute digunakan dalam hal pengiriman pesan dari node asal ke node tujuan. Untuk itulah dibutuhkan suatu protokol routing yang melakukan pencarian rute tersebut.

Pemilihan routing protocol yang tepat ini diperlukan dalam skenario jalan kota (urban) dan pinggiran kota (rural). Terdapat tiga klasifikasi protokol jaringan yang digunakan yaitu protokol reaktif, proaktif dan hybrid. Tujuan dari protokol routing adalah untuk memiliki kecepatan yang efisien pembentukan antara sepasang node, sehingga pesan 
bisa disampaikan tepat pada waktunya. Dalam penerapannya, kinerja VANET juga sangat dipengaruhi oleh model propagasi [1]. Suatu bagian penting dari setiap simulasi jaringan nirkabel adalah pilihan tentang model propagasi yang akan digunakan untuk memodelkan kinerja saluran jaringan nirkabel atau set saluran. Untuk mengetahui kinerja dari varian model propagasi tersebut menggunakan model propagasi seperti freespace, tworayground, shadowing dan nakagami. Model ini diperlukan dalam simulator untuk menghitung kekuatan sinyal transmisi nirkabel di stasiun penerima.

Simulasi protokol routing dibuat menggunakan tools Network Simulator 2 (NS2) versi 2.35, Simulation for Urban Mobility (SUMO) dan rute yang akan digunakan diambil dari situs web OpenStreetMap. Adapun routing protokol yang digunakan seperti protokol reaktif yaitu temporally ordered routing algorithm (TORA), protokol proaktif seperti multi-path dynamic addressing routing (MDART) dan protokol hybrid zone routing protocol (ZRP).

Penelitian ini diterapkan pada peta jalan Kota Praya dan Bypass Lombok, alasan dipilihnya peta jalan Kota Praya karena keadaan lalu lintas di jalan Kota Praya yang padat dapat menyebabkan terjadinya kemacetan sehingga sangat cocok sebagai objek penelitian, begitu juga di Bypass Lombok sangat cocok menjadi objek penelitian dikarenakan keadaan lalu lintasnya di pinggiran kota juga sangat padat karena jalur yang digunakan menuju ke Bandara Internasional Lombok.

\section{TINJAUAN PUSTAKA}

Pada penelitian [2] bertujuan untuk menganalisa performa dari protokol DSR, AODV, dan TORA dengan perbandingan packet delivery ratio (PDR), end to end delay, routing load, packet loss percentage (PLP), dan debit antara ketiga protokol routing tersebut. Hasil yang didapatkan adalah protokol TORA pada jaringan dengan jumlah node sedikit dan kecepatan gerak yang rendah menghasilkan delay yang paling sedikit. Untuk kondisi jaringan yang padat dan kecepatan tinggi, delay dari protokol TORA menjadi lebih besar dibandingkan DSR dan AODV, dari sisi pesat transfer atau debit, protokol DSR menghasilkan kinerja yang terbaik pada jaringan dengan jumlah nodesedikit kinerja tersebut menurun seiring dengan kepadatan jaringan yang bertambah.

Pada penelitian [3] dilakukan pada jalan raya dengan perbandingkan terhadapa tiga macam protokol routing yaitu DSR, AODV dan MDART, hasilnya adalah dalam bentuk PDR dan throughput, dapat disimpulkan bahwa MDART berkinerja lebih baik dalam hal PDR karena mendapat nilai maksimum di antara protokol routing DSR dan AODV. Dan dalam hal throughput AODV berkinerja lebih baik dibandingkan protokol lainnya.

Pada penelitian [4] dilakukan pada peta dengan kondisi lingkungan urban (perkotaan) dengan perbandingan terhadap dua macam protokol routing yaitu ZRP dan GPSR pada jaringan VANET dengan berbagai parameter simulasi adalah menggunakan variasi jumlah node 20 sampai 100 node dengan kecepatan laju node adalah antara $30-50 \mathrm{~km} / \mathrm{h}$ (low speed) dan 50-80 km/h (high speed) dengan luas area simulasi adalah $800 \times 800 \mathrm{~m}^{2}$. Pada penelitian ini model propagasi yang digunakan adalah tworayground dan simulasi dilakukan selama 200 detik, sedangkan untuk mengukur kinerja masingmasing protokol routing parameter pengujian yang digunakan adalah throuhput, pdr, end to end delay, dan packet loss. Hasil kesimpulan pada penelitian ini menyatakan bahwa protokol ZRP memiliki kinerja yang lebih baik untuk pengiriman paket data, meskipun dengan nilai throughput yang rendah. Sementara itu GPSR kurang dapat diandalkan dalam pengiriman paket dari sumber ke tujuan, akan tetapi GPSR memiliki keunggulan dengan nilai delay yang rendah dan throughput yang tinggi.

Pada penelitian [5] dilakukan perbandingan terhadap kinerja beberapa variasi model propagasi yaitu diantaranya model propagasi free space, tworayground, shadowing, dan nakagami. Adapun parameter simulasi yang ditentukan pada penelitian tersebut adalah menggukan area simulasi $1000 \times 1000$ $\mathrm{m}^{2}$, jumlah variasi node yang dipakai adalah 500,55 , $75,100,125,150,175$, dan 200 , pada peta dengan kondisi lingkungan urban (perkotaan), dan menggunakan protokol routing AODV, waktu simulasi yang digunakan 100 detik, dan kecepatan pergerakan node adalah antara 8.33-13.89 meter/detik. Parameter pengujian yang digunakan untuk menguji kemampuan masing-masing model propagasi adalah throughput, packet loss, transmitted packet, dan received packet. Hasil yang diperoleh dari simulasi penelitian ini menunjukan bahwa model propagasi nakagami memiliki performa yang paling baik dibandingkan ketiga model propagasi lainnya, baik itu berdasarkan nilai throughput, packet loss, transmitted packet, maupun recived packet.

Pada penelitian [6] dilakukan perbandingan beberapa variasi model propagasi yaitu free space, tworayground, dan shadowing pada protokol routing AODV, pada peta dengan kondisi lingkungan urban (perkotaan), dengan parameter simulasi yang digunakan adalah kecepatan pergerakan node berada 
di kisaran antara $1 \mathrm{~m} / \mathrm{s}$ sampai $40 \mathrm{~m} / \mathrm{s}$, jumlah node berkisar antara 5 hingga 40 node, dengan parameter ukur yaitu packet delivery ratio (pdr), end to end delay (E2D), dan througput. Hasil yang didapat pada penelitian ini bahwa pada parameter ukur PDR model propagasi shadowing memiliki hasil yang baik, namun seiring dengan bertambahnya jumlah node maka model propagasi free space memilki performa yang lebih baik. Untuk througput rata-rata shadowing model memiliki nilai yang terbaik dari kedua model propagasi lainnya. Sedangkan untuk parameter ukur E2D model propagasi free space memiliki nilai yang baik diikuti dengan model shadowing.

Pada penelitian [7] dilakukan analisis terhadapa kinerja model propagasi tworayground, nakagami, dan shadowing dengan parameter simulasi yang dilakukan adalah jumlah node sebanyak 12 node $/ \mathrm{km} /$ lane, kecepatan gerak node $70-120 \mathrm{~km} / \mathrm{h}$ pada peta dengan kondisi lingkungan perkotaan (urban). Penelitian ini melakukan beberapa skenario simulasi yaitu, pada skenario pertama meggunakan sebuah node atau vehicle yang melakukan broadcast paket data ke node lainnya terlihat perbedaan hasil yang dihasilkan oleh beberapa model propagasi. Kemudian pada skenario percobaan kedua menggunakan parameter uji seperti skenario pertama akan tetapi node-node mengirimkan status status mereka secara continue, sedangkan salah satu node akan bertugas sebagai broadcaster paket data kepada node yang lainnya, hasilnya adalah model propagasi tworayground mengalami waktu delay yang terbesar bila dibandingkan dengan model propagasi lainnya (shadowing dan nakagami).

\section{Metode Penelitian}

\subsection{Identifikasi Kebutuhan Sistem}

Penelitian ini memiliki beberapa kebutuhan, yaitu perangkat keras yang digunakan pada penelitian ini adalah sebuah laptop dengan spesifikasi yang akan dirincikan pada sub bab 3.2 Spesifikasi perangkat keras, sedangkan untuk kebutuhan perangkat lunak merupakan sistem operasi dan aplikasi-aplikasi pendukung dalam penelitian yang akan dirincikan pada sub bab 3.3 Spesifikasi perangkat lunak.

\subsection{Kebutuhan Perangkat Keras}

Uji coba dilakukan dengan menggunakan Laptop ASUS X441S dengan spesifikasi perangkat yang dapat dilihat pada Tabel I dan parameter lingkungan uji coba penelitian yang digunakan pada NS-2 dapat dilihat pada Tabel I.
TABEL I SPESIFIKASI PERANGKAT KeRAS

\begin{tabular}{|l|l|}
\hline \multicolumn{1}{|c|}{ Komponen } & \multicolumn{1}{c|}{ Spesifikasi } \\
\hline CPU & Intel ${ }^{\sqrt{ }}$ Core N3060 CPU @ 2.48 GHz \\
\hline Sistem Operasi & Linux Ubuntu 16.04 LTS 32-bit \\
\hline Memori & $2,00 \mathrm{~GB}$ \\
\hline Harddisk & $500 \mathrm{~GB}$ \\
\hline
\end{tabular}

\subsection{Kebutuhan Perangkat Lunak}

Adapun perangkat lunak yang digunakan adalah sebagai berikut :

- Linux Ubuntu versi 16.04 LTS 32 bit sebagai Sistem Operasi yang dipakai.

- Network Simulator 2 (NS2) versi 2.35 untuk melakukan simulasi VANET.

- Simulation of Urban Mobility (SUMO) untuk membuat skenario mobilitas VANET.

- Java OpenStreetMap (JSOM) untuk menyunting peta yang didapat dari OpenStreetMap

- Microsoft Excel untuk membuat grafik hasil uji coba

\subsection{Diagram Alir Penelitian}

Gambar diagram Alir simulasi pada penelitian ini dapat dilihat pada Gambar 1.

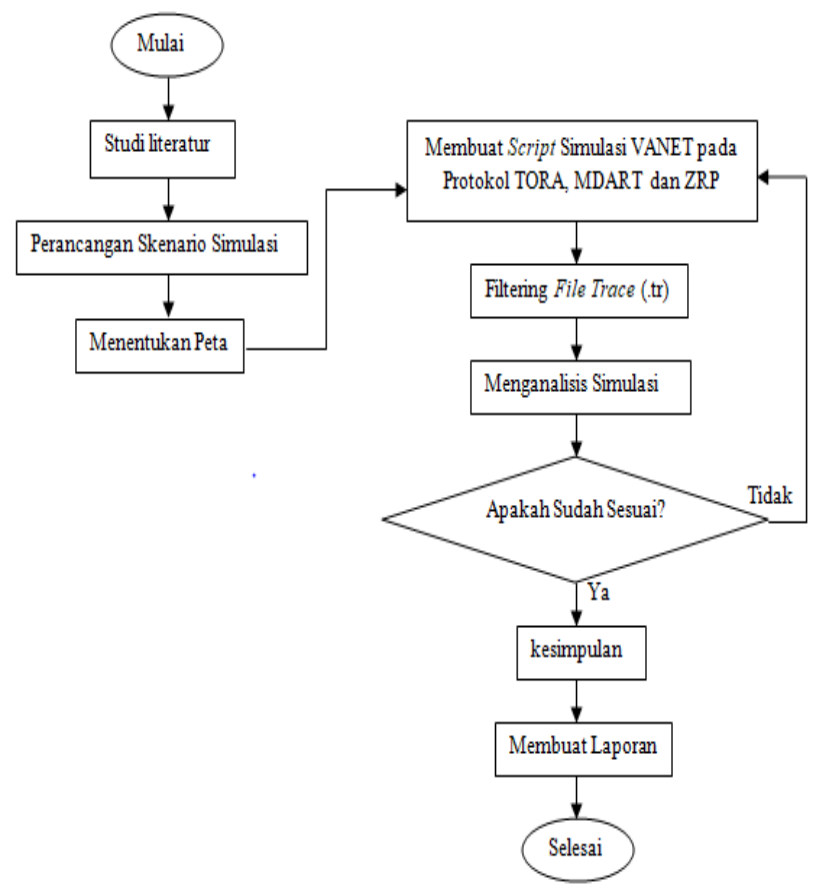

Gambar 1. Diagram Alir Penelitian 


\section{4. hasil dan Pembahasan}

Berikut ini merupakan hasil dari simulasi yang dilakukan pada aplikasi NS-2 untuk protokol routing TORA (Temporally Ordered Routing Algorithm), multipath dynamic addressing routing (MDART) dan protokol hybrid zone routing protocol (ZRP). File keluaran dari simulator NS-2 dikelola menggunakan script AWK, dengan script ini didapatkan hasil pengujian dari parameter yang digunakan.

\subsection{Hasil Simulasi Di Peta jalan Kota Praya}

Pada sub bab ini akan dijelaskan analisis throughput, PDR dan delay yang akan dibahas dalam sub bab 4.1.1, 4.1.2 dan 4.1.3.

\subsubsection{Analisis Throughput}

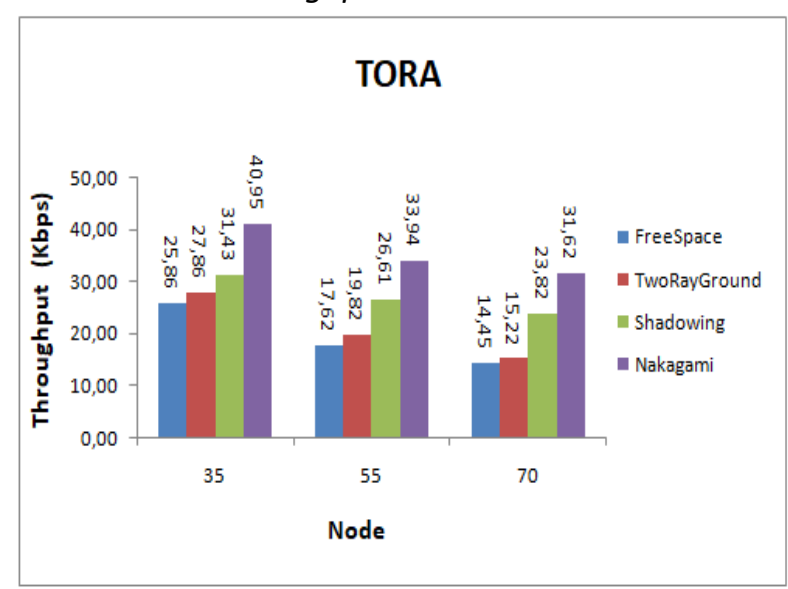

Gambar 2. Throughput protokol TORA

Pada Gambar 2 protokol TORA pada parameter throughput dengan luas area $1000 \times 1000 \mathrm{~m}^{2}$, terlihat bahwa nilai throughput yang paling tinggi pada propagasi nakagami dengan jumlah node 35 sebesar 40,95 Kbps. Sedangkan pada node 55 dan 70 nilai throughput terjadi penurunan dikarenakan seiring bertambahnya kecepatan node nilai throughput kedua protokol ini menurun karena semakin tinggi jumlah jumlah jarak antar node pun semakin menjauh. Dimana penyebabnya semakin tinggi kemungkinan terjadi link failure dan akibatnya nilai throuhgput menurun.

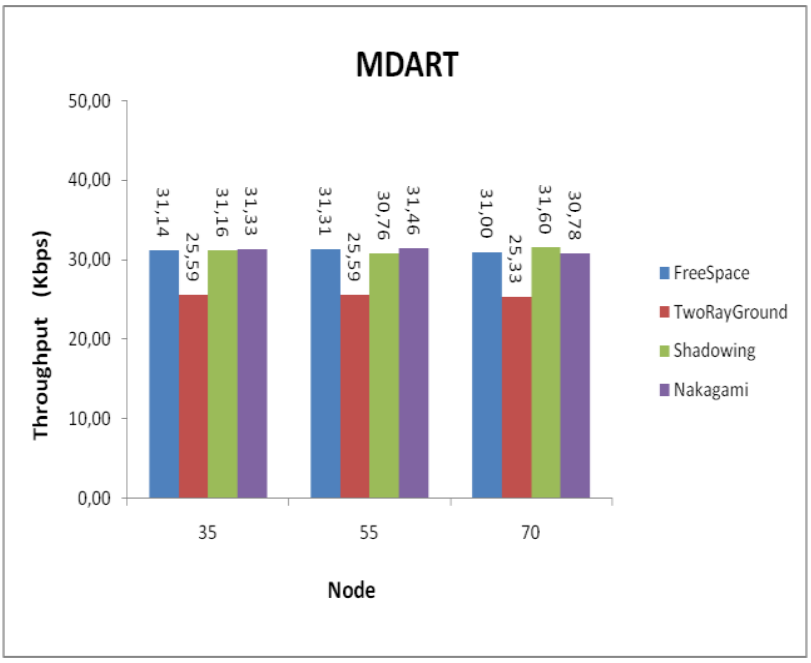

Gambar 3. Throughput protokol MDART

Pada Gambar 3 protokol MDART dengan luas area $1000 \times 1000 \mathrm{~m}^{2}$, pada propagasi freespace bahwa nilai throughput yang paling tinggi pada propagasi shadowing dengan jumlah node 70 sebesar 31.60 Kbps. Dari keempat propagasi tersebut bahwa propagasi tworayground memberikan hasil yang kurang baik.

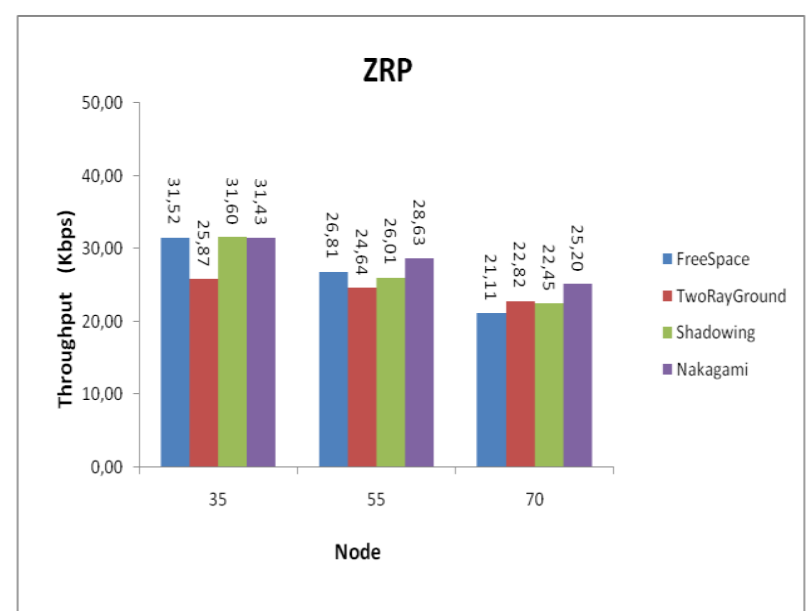

Gambar 4. Throughput protokol ZRP

Pada Gambar 4 protokol ZRP dengan luas area $1000 \times 1000 \mathrm{~m}^{2}$, terlihat bahwa semakin node bertambah maka throughput yang dihasilkan untuk semua propagasi cenderung menurun. Nilai throughput yang paling tinggi pada propagasi freespace dengan jumlah node 35 sebesar $31.52 \mathrm{Kbps}$ sehingga memberikan nilai throughput yang lebih baik dari propagasi lainnya. 


\subsubsection{Analisis Packet Delivery Ratio (PDR)}

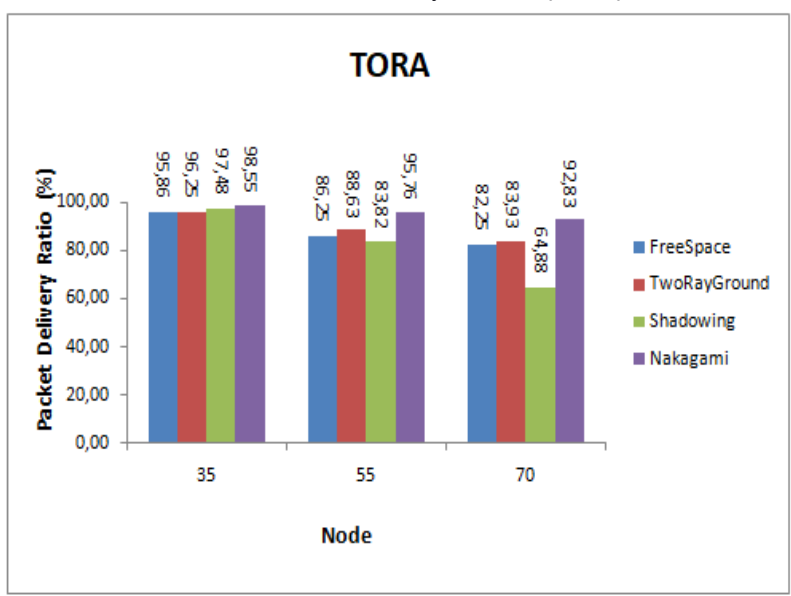

Gambar 5. Packet delivery ratio protokol TORA

Pada Gambar 5 protokol TORA dengan luas area $1000 \times 1000 \mathrm{~m}^{2}$ memiliki nilai yang dominan lebih tinggi dari protokol lainnya.. protokol ini memiliki performa yang cukup stabil dalam parameter PDR. Ini disebabkan informasi yang selalu diberikan kepada node sumber apabila terjadi link failure akibat perubahan topologi dalam jaringan.

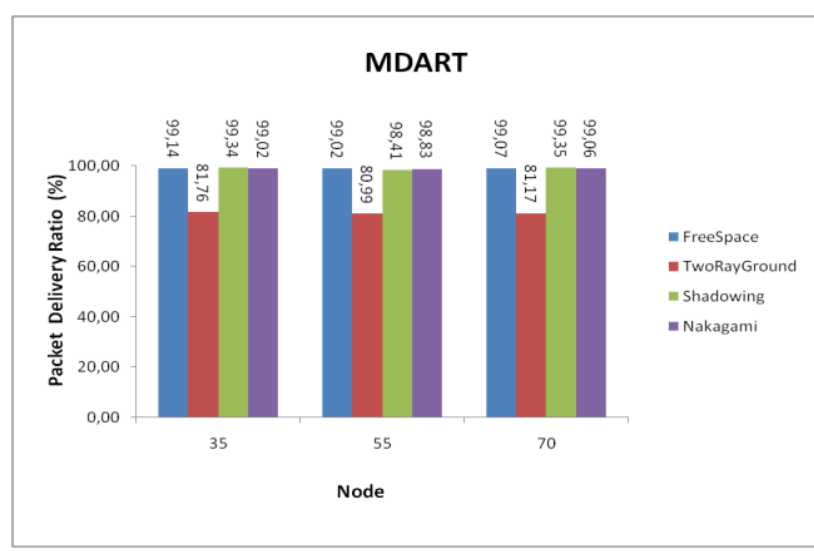

Gambar 6. Packet delivery ratio protokol MDART

Protokol MDART dengan luas area 1000×1000 $\mathrm{m}^{2}$, PDR menunjukkan data yang dikirim node asal ke node tujuan telah berhasil yang dinotasikan dalam satuan persen. Persentasenya semakin besar akan semakin baik. Terlihat seperti di Gambar 6 nilai PDR yang paling baik terletak di node 70 propagasi shadowing sebesar 99,35\%, dari keempat propagasi tersebut bahwa propagasi tworayground memberikan hasil yang kurang baik.

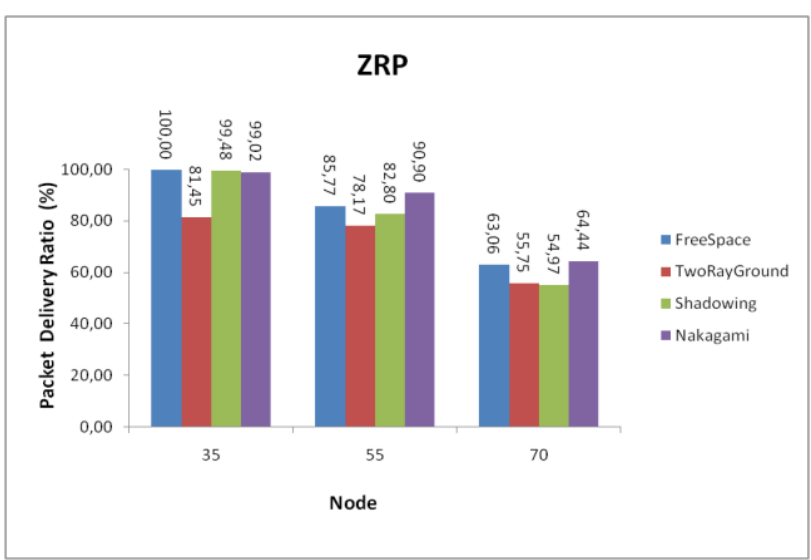

Gambar 7. Packet delivery ratio protokol ZRP

Pada lingkungan urban kecepatan ditentukan dengan nilai lebih kecil disesuaikan pada lingkungan perkotaan pada umumnya yaitu berkisar 50 sampai 80 $\mathrm{km} / \mathrm{jam}$. Protokol ZRP dengan luas area 1000×1000 $\mathrm{m}^{2}$, sehingga pada Gambar 7 pada protokol ZRP nilai PDR yang baik pada node 35 pada propagasi freespace mencapai nilai $100 \%$.

\subsubsection{Analisis Average End-To-End Delay}

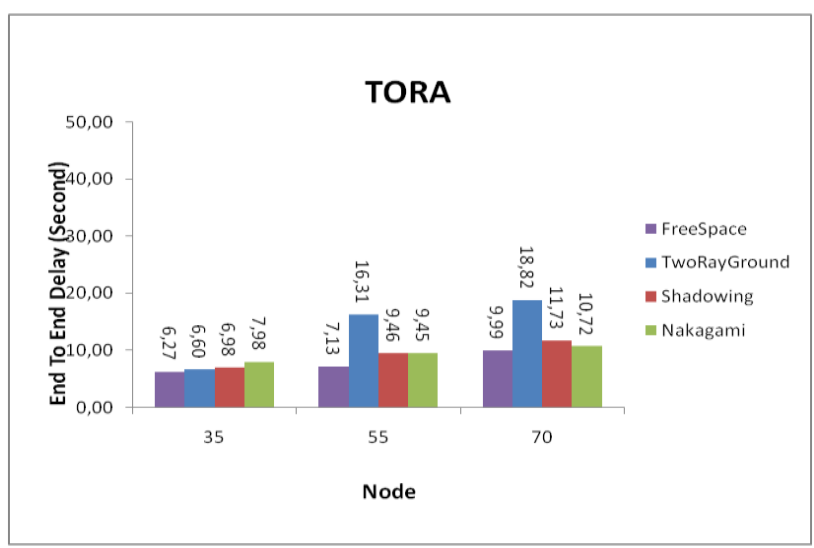

Gambar 8. Delay protokol TORA

Ketika proses pengiriman paket data pada suatu rute terjadi, tidak menutup kemungkinan akan terjadinya delay. Delay terjadi disebabkan karena beberapa hal yang terjadi pada saat proses pengiriman paket data tersebut seperti misalnya adanya antrian paket dan proses paket yang dikirim. Jika nilai delay semakin kecil, maka kualitas jaringan tersebut bagus, demikian juga sebaliknya jika nilai besar maka kualitas jaringan buruk. Pada Gambar 8 menunjukan nilai delay paling baik pada node 35 pada propagasi freespace 6,27 detik. 


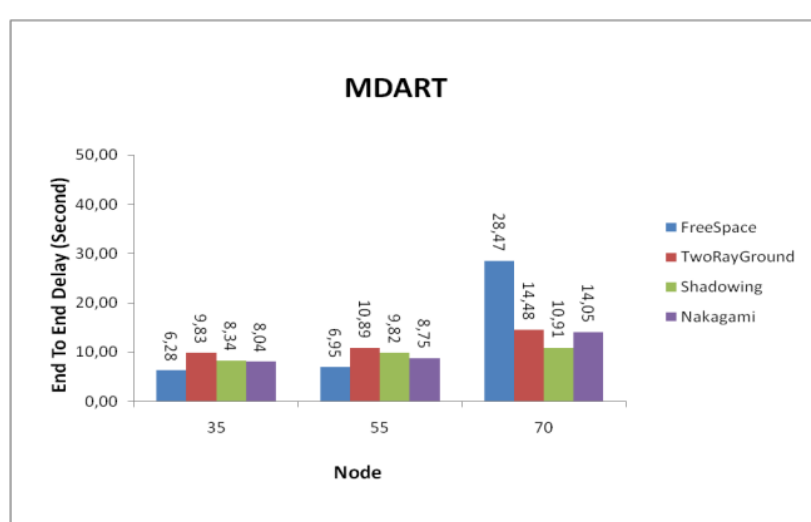

Gambar 9. Delay protokol MDART

Gambar 9 protokol MDART dengan luas area $1000 \times 1000 \mathrm{~m}^{2}$ menunjukan nilai delay paling baik pada node 35 pada propagasi freespace sebesar 6,28 detik. Seperti pada node 70 pada propagasi freespace dengan jumlah delay 28,47 detik sehingga nilai delay nya kurang baik.

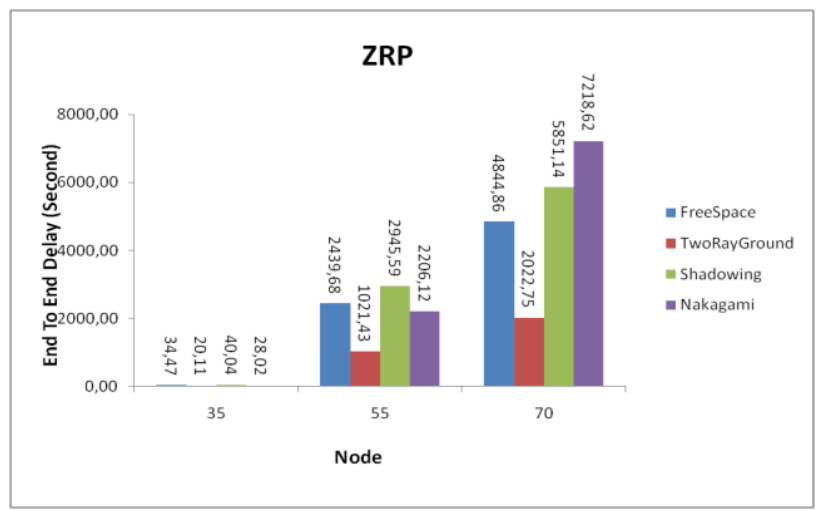

Gambar 10. Delay protokol ZRP

Pada Gambar 10 pada protokol ZRP dengan luas area $1000 \times 1000 \mathrm{~m}^{2}$ maka delay yang baik pada node 35 pada propagasi tworayground sebesar 20,11 detik. Dilihat dari nilai rata-rata yang dihasilkan pada uji coba end to end delay, semakin banyak jumlah node yang digunakan maka delay yang dibutuhkan akan semakin meningkat. Hal ini disebabkan oleh table routing node akan di update apabila ada jalur yang terputus, sehingga menyebabkan delay terus meningkat ketika node semakin banyak dan kemungkinan node yang terputus akan semakin besar.

\subsection{Hasil Simulasi Di Peta Jalan Bypass Lombok}

Pada sub bab ini akan dijelaskan analisis throughput, PDR dan delay yang akan dibahas dalam sub bab 4.2.1, 4.2.2 dan 4.2.3.

4.2.1 Analisis Throughput

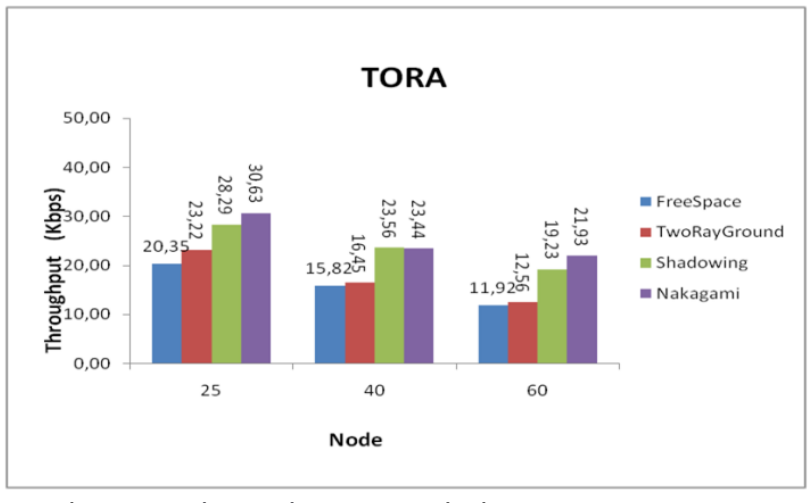

Gambar 11. Throughput protokol TORA

Pada Gambar 11 protokol TORA pada parameter throughput dengan luas area $1000 \times 1000 \mathrm{~m}^{2}$, terlihat bahwa nilai throughput yang paling tinggi pada propagasi nakagami dengan jumlah node 25 sebesar $30,63 \mathrm{Kbps}$. Sedangkan pada node 40 dan 60 nilai throughput terjadi penurunan dikarenakan seiring bertambahnya kecepatan node nilai throughput kedua protokol ini menurun karena semakin tinggi jumlah kecepatan jarak antar node pun semakin menjauh. Dimana penyebabnya semakin tinggi kemungkinan terjadi link failure dan akibatnya nilai throuhgput menurun.

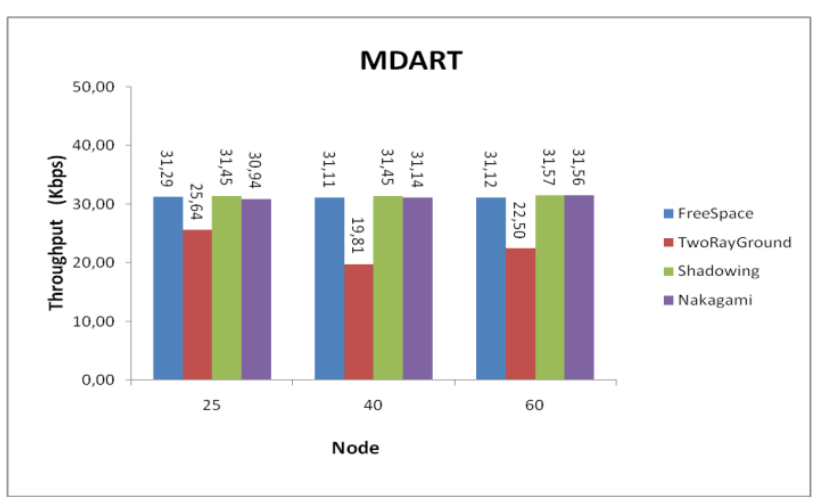

Gambar 12. Throughput protokol MDART

Nilai throughput dipengaruhi oleh beberapa hal, dimana salah satunya adalah konsistensi dari topologi jaringan tersebut dan proses pencarian jalur tersebut sehingga jalur tersebut terbentuk. Pada Gambar 12 protokol MDART dengan luas area $1000 \times 1000 \mathrm{~m}^{2}$, pada propagasi freespace bahwa nilai throughput yang paling tinggi pada propagasi nakagami dengan jumlah node 60 sebesar $31.56 \mathrm{Kbps}$. Dari keempat propagasi tersebut bahwa propagasi tworayground memberikan hasil yang kurang baik. 


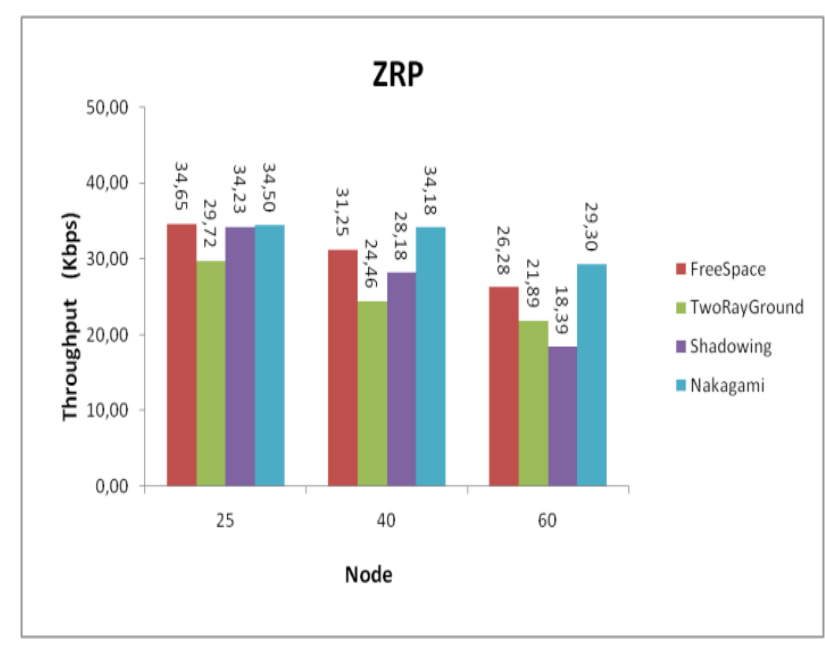

Gambar 13.Throughput protokol ZRP

Pada Gambar 13 protokol ZRP dengan luas area $1000 \times 1000 \mathrm{~m}^{2}$, terlihat bahwa semakin node bertambah maka throughput yang dihasilkan untuk semua propagasi cenderung menurun. Nilai throughput yang paling tinggi pada propagasi freespace dengan jumlah node 25 sebesar $34.65 \mathrm{Kbps}$ sehingga memberikan nilai throughput yang lebih baik dari propagasi lainnya.

\subsubsection{Analisis Packet Delivery Ratio (PDR)}

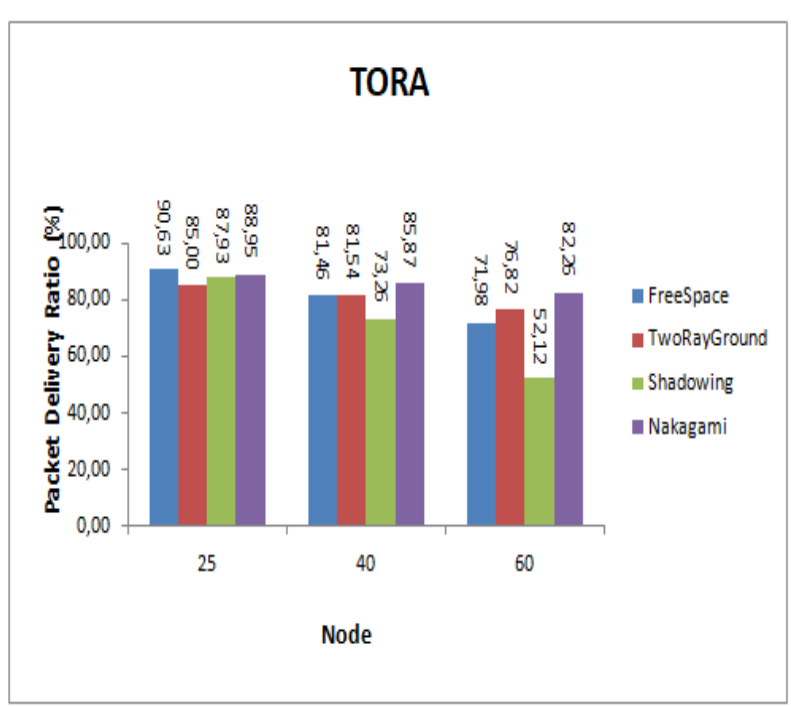

Gambar 14. Packet delivery ratio protokol TORA

PDR dipengaruhi oleh nilai throughput semakin tinggi nilai PDR suatu routing protocol semakin bagus juga routing protocol tersebut dalam menentukan atau mencari rute. Pada hasil rata-rata pada skenario di Bypass ini protokol TORA mengalami penurunan nilai PDR. Gambar 14 pada node 25 propagasi freespace senilai 90,63\% memiliki nilai yang dominan lebih tinggi dari propagasi lainnya. protokol ini memiliki performa yang cukup stabil dalam parameter PDR. Ini disebabkan informasi yang selalu diberikan kepada node sumber apabila terjadi link failure akibat perubahan topologi dalam jaringan selalu tersedia sehingga TORA yang mendukung multi route dapat memilih jalur lain untuk mengirimkan paketnya.

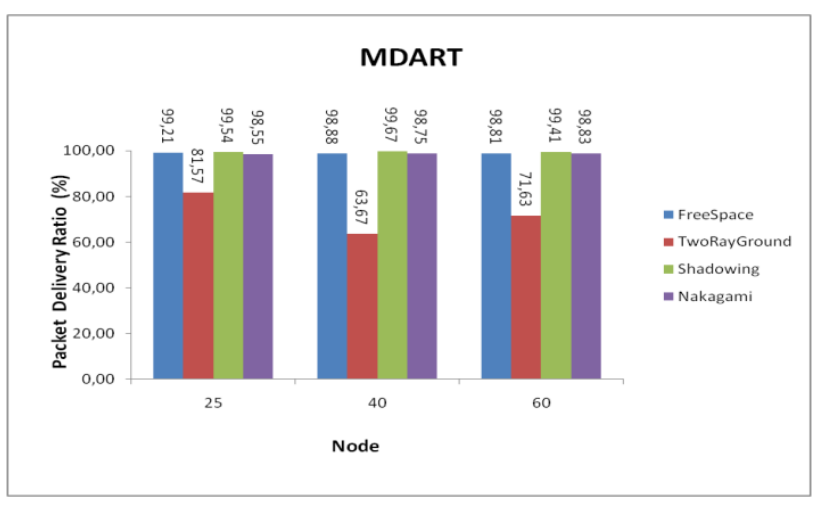

Gambar 15. Packet delivery ratio protokol MDART

PDR dipengaruhi oleh nilai throughput semakin tinggi nilai PDR suatu routing protocol semakin bagus juga routing protocol tersebut dalam menentukan atau mencari rute. Protokol MDART dengan luas area $1000 \times 1000 \mathrm{~m}^{2}$, seperti pada Gambar 15 nilai PDR yang paling baik terletak di node 40 propagasi shadowing sebesar 99,67\%, semakin tinggi nilai PDR semakin bagus pula routing protocol tersebut.

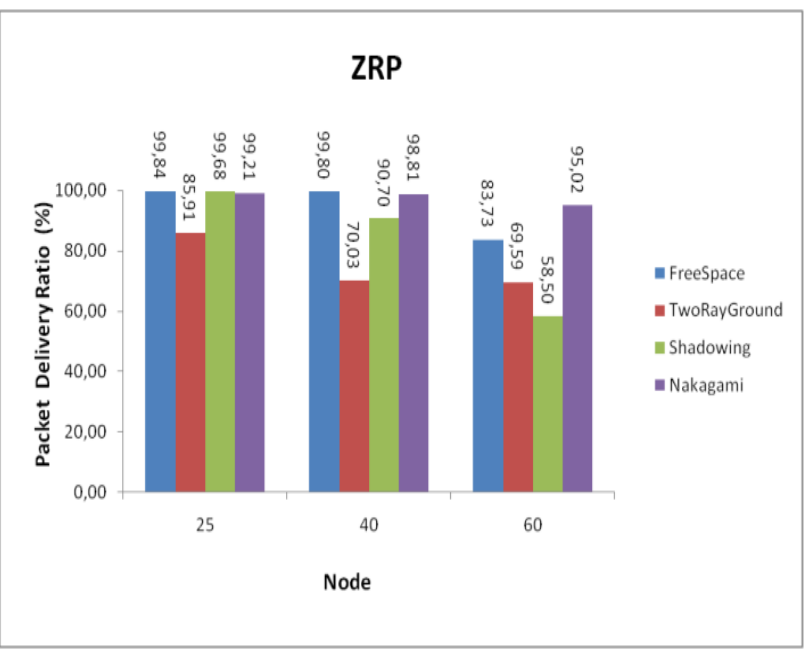

Gambar 16. Packet delivery ratio protokol ZRP

Pada Gambar 16 protokol ZRP dengan luas area $1000 \times 1000 \mathrm{~m}^{2}$. Pada protokol ZRP nilai PDR yang baik pada node 25 pada propagasi freespace mencapai nilai $99.84 \%$. 


\subsubsection{Analisis Average End-To-End Delay}

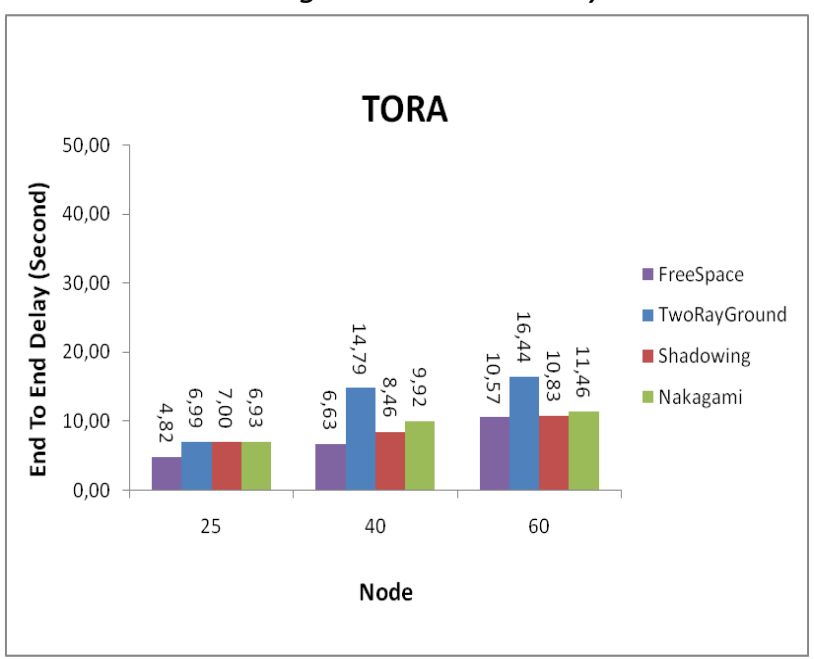

Gambar 17. Delay protokol TORA

Pada Gambar 17, dimana yang digunakan adalah protokol routing TORA, menunjukan nilai delay paling baik pada node 25 dengan propagasi freespace 4,82 detik.

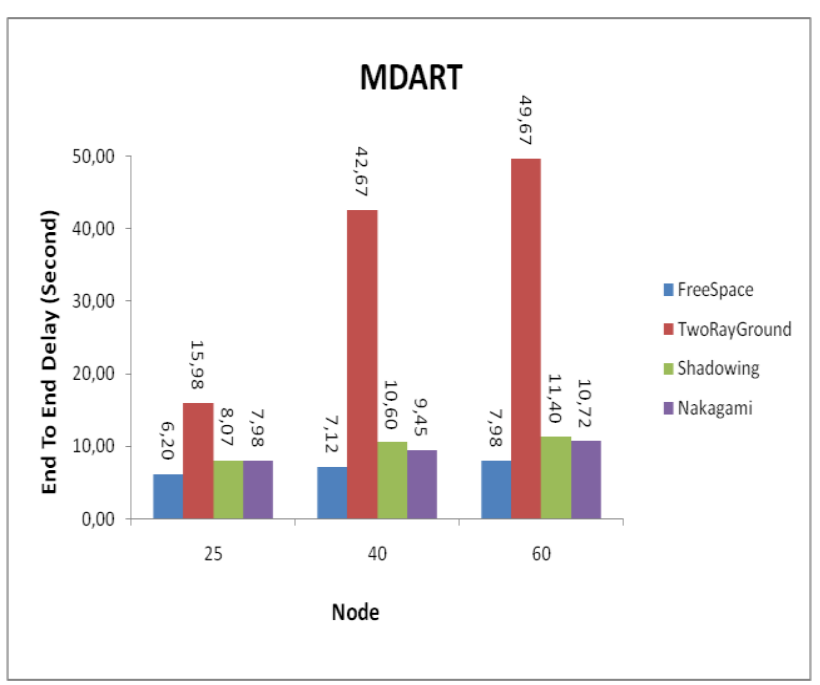

Gambar 18. Delay protokol MDART

Gambar 18. protokol MDART dengan luas area $1000 \times 1000 \mathrm{~m}^{2}$ menunjukan nilai delay paling baik pada node 25 pada propagasi freespace sebesar 6,20 detik. Pada node 60 dengan propagasi tworayground terdapat jumlah delay 49,67 detik sehingga nilai delay nya kurang begitu baik.

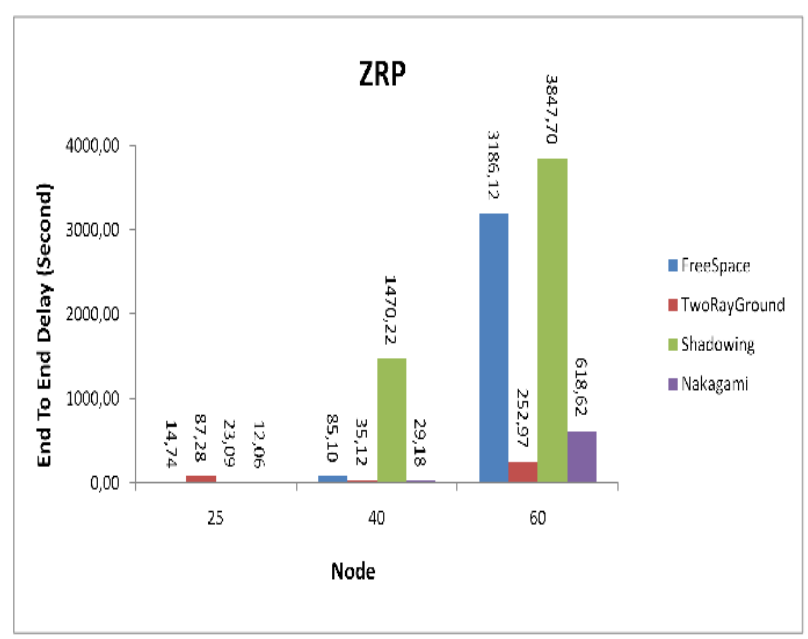

Gambar 19. Delay protokol ZRP

Pada Gambar 19 nilai end to end delay untuk ZRP masih tinggi dari pada protokol TORA dan MDART dikarenakan pergerakan node yang random dilihat dari nilai rata-rata yang dihasilkan pada uji coba end to end delay, semakin banyak jumlah node yang digunakan maka delay yang dibutuhkan akan semakin meningkat. Semakin tinggi kecepatan juga mempengaruhi kemungkinan terjadinya topologi atau kegagalan route atau link failure semakin besar.

\section{KESIMPULAN DAN SARAN}

\subsection{Kesimpulan}

Dari pengujian yang telah dilakukan, dapat ditarik beberapa kesimpulan sebagai berikut :

1. Pada skenario urban atau di peta jalan Kota Praya dengan luas area $1000 \times 1000 \mathrm{~m}^{2}$, nilai ratarata yang terbaik pada protokol TORA parameter througput sebesar $35,50 \mathrm{Kbps}$ pada propagasi nakagami dan delay sebesar 7,79 detik pada propagasi freespace, untuk nilai rata-rata parameter PDR diperoleh sebesar 99,08\% pada protokol MDART propagasi freespace.

2. Pada skenario rural atau Bypass Lombok parameter throughput hasil nilai rata-rata yang terbaik didapatkan pada protokol ZRP 32,66 Kbps pada propagasi nakagami. Pada protokol MDART parameter PDR nilai rata-rata sebesar 99,54\% pada propagasi shadowing dan untuk parameter delay sebesar 7,10 detik pada propagasi freespace.

3. Dari hasil percobaan pada skenario urban di jalan peta Kota Praya protokol yang cocok untuk digunakan yaitu protokol TORA dan di sisi rural protokol yang cocok digunakan yaitu protokol 
MDART, serta dari ke dua skenario tersebut propagasi yang bagus untuk digunanakan yaitu propagasi nakagami.

\subsection{Saran}

Berdasarkan kesimpulan yang sudah dipaparkan, maka dapat diusulkan beberapa saran berikut demi pengembangan kedepannya, seperti :

1. Melakukan penelitian serupa dengan menambahkan beberapa algoritma yang bisa digunakan serta menggunakan NS3 agar VANET benar-benar bisa diimplementasikan kedepannya.

2. Melakukan penelitian selain protokol TORA, MDART dan ZRP pada jaringan VANET.

\section{DAFTAR PUSTAKA}

[1] S. Ramadhani, and R. Anggoro, "Studi perbandingan kinerja model transmisi TwoRayGround dan Nakagami pada OLSR di," J. Teknik ITS, vol. 5, no. 2, 2016.

[2] A. K. Gupta, H. Sadawarti, and A. K. Verma, "Performance analysis of AODV, DSR \& TORA Routing Protocols," vol. 2, no. 2, 2010. Int. J. Engineering and Tecknology, vol. 2. no. 2, 2010.

[3] V. Jain and R. S. Kushwah, "Review of various VANET protocols using NS-2 simulator," Int. J. Comput., vol. 4, no. 7, 2016.

[4] A. Ardiansyah, D. Perdana, and R. F. Sari, "Performance comparison of GPSR and ZRP routing protocols in VANET environment," IEEE region 10
TENSYMP, 2016.

[5] R. C. Poonia and V. Singh, "performance evaluation of radio propagation model for vehicular adhoc networks using vanetmobisim and NS-2," Int. J. Distributed and Parallel Systems, vol. 3, no. 4, hal 145-155, 2012.

[6] B. Makodia, D. Marsona, "Effect of radio-wave propagation model on network performance with AODV routing protocol for IL-VANET," Int. Arch.App. Scl. Technol, vol 5, hal 13-18, 2014.

[7] K. A. Hafeez, L. Zhao, Z. Liao, and B. N. Ma, "The optimal radio propagation model in VANET The optimal radio propagation model in VANET," Int. J. Elektrical and Compt. Engineering, 2015.

[8] P. D. Setiady, F. A. Yulianto, and A. Herutomo, "Analisis perbandingan performansi routing protocol MDART dan ZRP pada jaringan vehicular ad hoc network," J. Fak. Teknik Informatika, Univ. Telkom, 2014.

[9] E. Haryatmi, B. Soerowirdjo, and A. B. Mutiara, "Pengaruh propagasi terhadap komunikasi data pada jaringan nirkabel," ISBN: 979-756-061-6, 2005.

[10] M. D. Agustya, "Analisis performa proactive routing protocol DSDV dan OLSR pada vehicular adhoc network (VANET) menggunakan NS-3," skripsi, Sepuluh Nopember Intitute of Technology, 2015.

[11] P. K. Singh, "Influences of TwoRayGround and Nakagami propagation model for the performance of adhoc routing protocol in VANET," Int. J. comput. applications, vol. 45, no. 22, pp. 1-6, 2012. 